\title{
La composición social del Ejército del Centro, primer baluarte de la causa realista (1810-1812)/
}

\section{The Social Composition of Ejército del Centro, the First Bastion of the Realist Cause (1810-1812)}

\author{
Juan José Benavides Martínez \\ ORCID iD: http:/orcid.org/ 0000-0002-7456-4840 \\ Universidad del País Vasco
}

El 16 de septiembre de 1810 estalló en Dolores una rebelión liderada por el cura Hidalgo e Ignacio Allende. El brigadier Félix Calleja, comandante militar de San Luis Potosí, formó un contingente de casi tres mil hombres, al que a finales de octubre se unió otro de tamaño similar procedente de México y Puebla al mando de Manuel de Flon, intendente de Puebla. Así se formó el Ejército del Centro que, con unos seis mil hombres, fue la primera fuerza que derrotó a los insurgentes. El análisis de este ejército aporta un mayor conocimiento de la respuesta de las autoridades frente a la insurgencia.

Palabras Clave: Guerra de Independencia; México; Milicias; Félix Calleja; Historia Militar.

On September 16, 1810 exploded a rebellion led by father Hidalgo and Ignacio Allende in Dolores. Félix Calleja, San Luis Potosî's military commander, formed a contingent of nearly three thousand men who, at the end of October, joined another of similar size from Mexico and Puebla under the command of Manuel de Flon, Puebla's Governor. In this way was formed the Ejército del Centro, which, with about six thousand men, was the first force that defeated the insurgents. The analysis of this army brings a greater understanding of the response of the authorities against the insurgency.

KeYwords: War of Independence; Mexico; Militia; Felix Calleja; Military History.

Copyright: (C) 2018 CSIC. Este es un artículo de acceso abierto distribuido bajo los términos de la licencia de uso y distribución Creative Commons Reconocimiento 4.0 Internacional (CC BY 4.0). 


\section{Introducción}

El presente texto tiene como objetivo fundamental señalar algunos de los motivos por los que una parte de la población novohispana, guiada por algunas élites locales, tomó partido por la denominada «causa realista» durante la contienda civil que fue la guerra de independencia. ${ }^{1}$ Para ello se ha realizado un análisis detallado de las principales características de la primera fuerza que se enfrentó y derrotó a los insurgentes, el Ejército del Centro, y de los hombres que lo conformaron. Dejando en segundo plano las cuestiones castrenses y centrando el enfoque en los aspectos sociales, en consonancia con la historiografía reciente de temática militar, se analiza la formación del Ejército del Centro tras el estallido insurgente, así como su organización interna y los cuadros de mando y tropas que lo conformaban. Estos puntos aportarán un mayor conocimiento del sistema defensivo novohispano a finales del periodo colonial y de las características de la respuesta militar de las autoridades frente a la insurgencia. ${ }^{2}$

Como es bien sabido, el 16 de septiembre de 1810 estalló en el pueblo de Dolores una rebelión liderada por el cura Hidalgo e Ignacio Allende. El brigadier Félix María Calleja del Rey, comandante militar de San Luis Potosí, salió a perseguir a los rebeldes al frente de un contingente de casi tres mil hombres, que él mismo había formado con los regimientos milicianos de la región y alistando voluntarios. A finales de octubre a esta fuerza se le unió otra de tamaño similar procedente de México y Puebla al mando de Manuel de Flon, conde de la Cadena e intendente de Puebla,

1 Si bien, en los comienzos de la lucha armada, los líderes insurgentes proclamaron su adhesión a Fernando VII y la defensa de sus derechos, el término de «realista» se ha utilizado tradicionalmente para referirse a la contrainsurgencia. Por ello, al hablar de «causa realista» nos referimos a los hombres que luchaban por el mantenimiento del orden virreinal frente a los insurgentes liderados por Hidalgo y Allende.

2 La historiografía americanista se ha enriquecido notablemente durante las últimas décadas con numerosos y valiosos estudios sobre la institución militar colonial y sobre la contrainsurgencia en el periodo de las independencias. Estos trabajos han superado la visión tradicional y se centran en aspectos sociales, políticos y económicos. Se plantean el análisis de la estructura defensiva del imperio como una aproximación a la América de ese momento, basándose en la idea de que la estructura defensiva reflejaba la sociedad en que se desarrollaba, no una relación de sometimiento. También analizan la inclusión de buena parte de la población americana dentro de la estructura militar durante los convulsos años finales del periodo colonial, y las importantes consecuencias económicas, sociales y políticas que acarreó, tanto durante las guerras de independencia como en la conformación de las primeras repúblicas. Para el caso mexicano cabría señalar: Archer, 1989; 2002a; 2002b. Kalhe, 1997. También, a nivel general, son reseñables otras aportaciones: Costeloe, 1989. Albi, 1990. Marchena, 2005. Asimismo, para el caso del ejército bolivariano en la Gran Colombia: Thibaud, 2003. 
formándose así el denominado Ejército del Centro, del que Calleja se convirtió en general.

Esta tropa, formada por unos seis mil hombres, fue la primera fuerza que derrotó a los insurgentes, y jugó un papel fundamental para el sostenimiento de la autoridad virreinal durante el año y medio que estuvo en campaña por buena parte del territorio novohispano, lo que le otorga al tema un valor estratégico. ${ }^{3}$

\section{Los ecos del grito. Félix Calleja y la reacción realista potosina}

En la primavera de 1808, las abdicaciones de Bayona marcaron el inicio de un periodo convulso en la Monarquía, que supuso la ruptura con el Antiguo Régimen y su desintegración en múltiples estados independientes. ${ }^{4} \mathrm{~A}$ medida que la noticia se difundía por la Península comenzaron los levantamientos contra los franceses y se formaron juntas de gobierno fieles a Fernando VII. En América se produjo la misma reacción de lealtad al rey «cautivo» pero, en general, los intentos de formar juntas no fueron exitosos. ${ }^{5}$

En Nueva España, tras la caída del proyecto juntista en septiembre de 1808 por la intervención del grupo peninsular de la capital, que derrocó al virrey Iturrigaray, ${ }^{6}$ el descontento de varios sectores de la sociedad fue creciendo y estalló el 16 de septiembre de 1810 en Dolores. Liderados por

3 Este artículo es la continuación de un primer estudio realizado sobre el papel de Félix Calleja en la reacción potosina ante el estallido insurgente. Benavides, 2016.

4 El 19 de marzo de 1808 Carlos IV se vio obligado a abdicar en su hijo Fernando tras los sucesos de Aranjuez, que también provocaron la destitución del valido Godoy. Napoleón, que, tras la firma del Tratado de Fontainebleau (27 de octubre de 1807) había desplegado sus tropas por la geografía española con la excusa de invadir Portugal, citó en Bayona a ambos para mediar en su disputa, ya que Carlos IV consideraba ilegítima su abdicación. Presionados por Bonaparte, Fernando abdicó en Carlos y este en Napoleón, que entregó la Corona a su hermano José. Entre la gran cantidad de trabajos sobre este periodo, que la historiografía ha denominado revolución hispánica, cabría destacar, por citar alguno: Annino y Guerra, 1991. Portillo, 2006.

5 Benavides, 2016, 223. La legitimidad de las juntas se fundamentaba en argumentos que mezclaban tradiciones jurídicas medievales y el concepto moderno de soberanía del pueblo. Guedea, 2005, 220-221. Véase también Chust, 2007.

6 El ayuntamiento de México planteó la formación de una junta novohispana presidida por el virrey Iturrigaray. Este apoyó la propuesta, lo que disgustó al grupo peninsular, que dominaba la Audiencia, el Consulado y el cabildo catedralicio. La madrugada del 16 de septiembre de 1808 un grupo de peninsulares tomó el palacio virreinal, apresaron a Iturrigaray y nombraron como nuevo virrey al oficial de mayor graduación de la ciudad, el mariscal Garibay. Sobre este tema véase: Hamnett, 1986. Navarro, 2009. Ruiz de Gordejuela, 2012. 
el cura Miguel Hidalgo y el capitán miliciano Ignacio Allende, los rebeldes formaron una fuerza, marcharon sobre Guanajuato y enviaron agentes a Querétaro y San Luis Potosí para extender la revuelta. ${ }^{7}$ Dos días después, el 18 de septiembre, fueron capturados en las proximidades de la capital potosina dos emisarios que trataban de reunir hombres de las haciendas de la zona para entrar en la ciudad. La noticia fue comunicada de inmediato al brigadier Calleja, comandante militar de la región. ${ }^{8}$

Félix María Calleja del Rey (Medina del Campo, Valladolid, 1753) comenzó su carrera militar como cadete en el Regimiento de Infantería de Saboya en 1772, con 19 años. Participó en las campañas de Argel, Menorca y Gibraltar, consiguiendo ascender a capitán, y fue director del Colegio Militar del Puerto de Santa María (Cádiz), hasta que en 1789 pasó a Nueva España tras ser agregado al Regimiento de Infantería de Puebla. Sin embargo, apenas estuvo unos meses en su destino porque su traslado formaba parte de un proyecto impulsado por la Corona para conocer con mayor exactitud todas sus posesiones y modernizar la administración del imperio. Por ello, cumpliendo las órdenes de los virreyes Revillagigedo (1789-1794), con quién viajó desde Cádiz, y Branciforte (1794-1798), revistó y reformó varios cuerpos milicianos del norte novohispano, además de realizar un completo informe sobre las Provincias Internas Orientales. ${ }^{9}$

En 1796, ascendido a teniente coronel, fue destinado a San Luis Potosí para hacer operativas las milicias recientemente establecidas en la región. En la capital potosina pactó la aplicación de las directrices virreinales con las élites locales, poniendo en marcha los regimientos milicianos, lo que le valió el ascenso a coronel y su designación como comandante de la $10^{\mathrm{a}}$ Brigada de milicias, con sede en San Luis. ${ }^{10}$ Calleja se ganó el apoyo y respeto de los oficiales, consiguiendo que las milicias a su cargo se mantuvieran razonablemente adiestradas. Su autoridad y eficiencia al frente de la brigada, unidas a las interinidades que se sucedieron al frente de la intendencia, favorecieron que se fuera configurando como el personaje de

7 Esta revuelta fue precedida por varias conspiraciones que fueron desbaratadas y su comienzo se precipitó porque fue descubierta. Van Young, 2007, 89-90. La independencia de México ha sido uno de los temas más tratados por la historiografía. Simplemente cabría destacar algunas aportaciones, en las que se puede encontrar la mayor parte de la bibliografía sobre el tema: Ávila y Guedea, 2007. Rodríguez, 1992. Vázquez, 1997.

8 Benavides, 2016, 223-224.

9 Ibidem, 224. Ortiz, 2003, 339-341.

10 Sobre el plan de brigadas, que dividía de Nueva España en diez distritos militares: Archer, 1983, 149-153. 
mayor influencia en la región, y en 1807 consolidó su liderazgo casándose con María Francisca de la Gándara, una criolla perteneciente a una de las familias más ricas e influyentes de la provincia. ${ }^{11}$

$\mathrm{Al}$ enterarse de lo acontecido en Dolores por la confesión de los rebeldes capturados, dispuso una serie de medidas para proteger la región: controles en caminos, barricadas en accesos a la ciudad, recompensas a delatores... Pero además organizó una fuerza para lanzarse en persecución de los insurgentes, para lo cual mandó reunir en San Luis los cuerpos milicianos de la provincia y comenzó a alistar voluntarios. En el verano de 1808, el comandante ya había dado muestras de su manera de actuar, firme y en defensa de la legalidad vigente, en momentos de crisis. Cuando llegó a San Luis la noticia de las abdicaciones de Bayona y la sublevación consecuente organizó un homenaje al rey depuesto. Luego, el virrey Iturrigaray (1804-1808), temeroso ante un posible ataque extranjero, le destinó a Veracruz para encargarse de su defensa. El 14 de septiembre llegó a México para recoger sus órdenes, pero fue despachado nuevamente a San Luis. ${ }^{12}$ Posteriormente, durante lo que Calleja denominó «arresto del virrey Iturrigaray por una conmoción popular», se encargó del mantenimiento del orden en la ciudad y de la seguridad personal del nuevo virrey, Garibay. El encargo de estas importantes comisiones demuestra su buena reputación y la confianza que las autoridades virreinales tenían en él. Su buen hacer le valió el ascenso a brigadier y lo consolidó como uno de los hombres fuertes del virreinato. ${ }^{13}$

\section{El germen de un ejército: la fuerza realista potosina}

A comienzos de octubre Calleja se trasladó con las milicias potosinas a la hacienda de la Pila (20 kilómetros al sur de San Luis), donde organizó

11 Benavides, 2016, 224. Calleja fue uno de los principales protagonistas de la guerra de independencia de Nueva España. Los insurgentes lo consideraron el más cruel de sus enemigos, sin embargo, su figura ha pasado bastante desapercibida por la historiografía. Entre los estudios específicos sobre este personaje podrían destacarse: Benavides, 2014. Bustamante, 1828. Ferguson, 1973. Ortiz, 2003.

12 Benavides, 2016, 224-225. Según Primo Feliciano Velázquez el virrey le propuso apoyar el proyecto juntista novohispano, oferta que Calleja rechazó porque consideraba que no era leal a la Corona. Tras comprobar que no contaba con su apoyo, a Iturrigaray no le interesaba que estuviera ni en la ciudad ni al mando de un importante contingente de tropas en Veracruz, así que lo mandó de regreso a San Luis. Velázquez, 1982, III, 14-15.

13 Benavides, 2016, 225. 
una fuerza expedicionaria con el apoyo mayoritario de la sociedad local. ${ }^{14}$ Demostró ser un auténtico líder regional al conjugar los esfuerzos de las autoridades, que siguieron sus órdenes al pie de la letra (en especial el intendente Acevedo), de los mineros, que le enviaron plata y pólvora, de los grandes hacendados, que le suministraron tropas, caballos y mulas, de los artesanos, que fabricaron armas y pertrechos, de los arrieros, que transportaron los suministros, y de gran parte de los vecinos ilustres, que formaron la oficialidad, así como de los peones y rancheros, que integraron la tropa. ${ }^{15}$

La defensa de la provincia de San Luis siempre estuvo a cargo de milicias, unas unidades armadas pero no militares, que se convirtieron en el sector más numeroso del sistema defensivo americano tras la derrota española en la guerra de los Siete Años (1756-1763), cuando los Borbones vieron la necesidad de que los habitantes de América contribuyeran a defender el territorio. Desde entonces se establecieron por todo el imperio cuerpos milicianos para la defensa y el mantenimiento del orden a nivel regional, formados por vecinos que recibían entrenamiento militar. ${ }^{16}$ En Nueva España la reforma se inició en 1764, cuando fue enviado el teniente general Juan de Villalba como inspector de tropas, aunque la resistencia de algunas autoridades provocó que el proceso no se consolidara hasta que en 1794 el virrey Branciforte, ante la inminencia de una guerra con Francia, pusiera en práctica el plan de reorganización del sistema defensivo diseñado por el coronel Antonio Crespo. ${ }^{17}$

En 1810 había tres cuerpos milicianos en la región potosina: los Regimientos Provinciales de Dragones de San Luis y San Carlos, formados por 12 compañías fijadas en diversas poblaciones y haciendas del altiplano

14 En este caso, el término «expedicionario», usado en la documentación y en la historiografía para referirse a los regimientos profesionales enviados desde la Península para luchar en Nueva España, se utiliza en un sentido literal, ya que hace referencia a una fuerza, la potosina, que sale en expedición contra el enemigo.

15 «el pueblo bajo lo miraba [a Calleja] con afectuoso respeto, llamándole, como sus mismos soldados, el amo don Félix». Núñez, 1950, 43. Benavides, 2016, 226. Bernal, 2005, 162.

16 Las milicias, por sus implicaciones sociales, su protagonismo en la lucha armada por la independencia y su influencia en la organización de los sistemas defensivos de las repúblicas americanas, han merecido la atención de varios autores en las últimas décadas: Chust y Marchena, 2007. Marchena, Caballero y Torres, 2005. Marchena y Kuethe, 2005. Suárez, 1984. Ruiz, 2009. Thibaud, 2003.

17 Sobre las reformas militares en Nueva España, la evolución de las milicias durante la guerra de independencia y su influencia en la organización militar mexicana, véase: Archer, 1983. Guzmán, 2002, 471-488. Kahle, 1997. Mc Alister, 1982. Ortiz, 2014. Vega, 1986. 
y con una fuerza total de 820 hombres ${ }^{18}$ y el Cuerpo de Caballería de la Frontera del Nuevo Santander, cuyas seis compañías se asentaban en las subdelegaciones de Valles y Rioverde y contaba con 360 plazas. $^{19}$

\section{MAPA 1}

\section{COMPAÑIIAS DE LOS REGIMIENTOS MILICIANOS EN LA PROVINCIA DE SAN LUIS POTOSÍ}

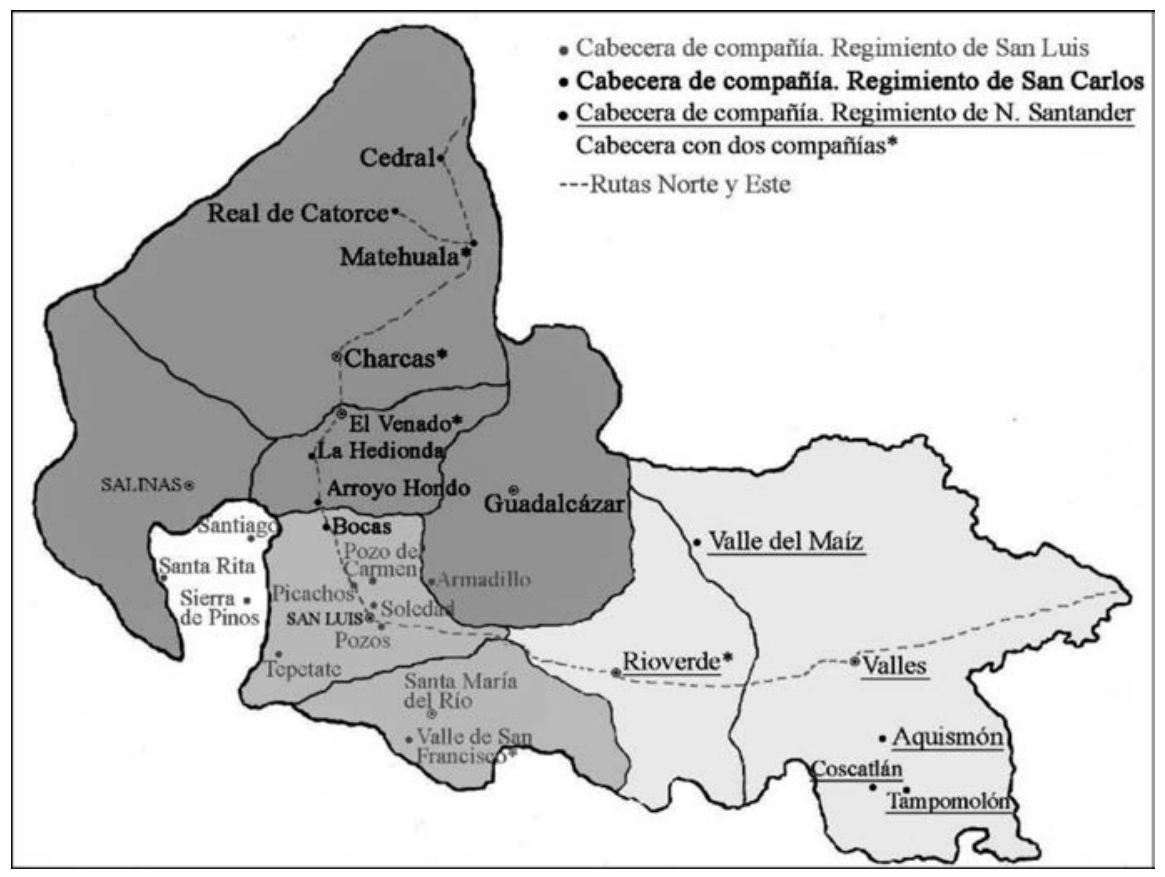

Elaboración propia.

Además, con los voluntarios que iban llegando Calleja formó dos nuevos regimientos, uno de caballería, el Cuerpo de Lanceros Montados de San Luis, denominados «Fieles del Potosí», con 1.230 hombres; y otro de

18 Incluido el pie veterano, los militares profesionales encargados de la instrucción de los milicianos. Instrucción entregada al coronel Salcedo para el restablecimiento de los cuerpos provinciales en San Luis Potosí, México, 19 de noviembre de 1794, Archivo General de Simancas (AGS), Secretaría de Guerra (SGU), 7002, exp. 1.

19 Sobre la formación y evolución de estos regimientos véase: Benavides, 2014, 59-249. Rangel, 2008. 
infantería, el Cuerpo de Patriotas de San Luis, conocidos como «los Tamarindos» por el color de su uniforme, con 400 plazas. $^{20}$

En total, la fuerza potosina quedó formada por cinco cuerpos milicianos, uno de infantería, dos de dragones y dos de caballería, y contaba con 2.827 hombres (2.427 montados y 400 a pie), de los cuales 157 eran oficiales y solamente había 40 militares profesionales. ${ }^{21}$ Calleja, que consiguió hacer frente a importantes dificultades para establecer este contingente (alistamientos, adiestramiento, suministros, financiamiento...) en apenas un mes, no tenía grandes expectativas puestas en él por sus carencias en armamento (escasez de armas de fuego y sin artillería) y por la falta de entrenamiento de la mayoría de los hombres. Pero sobre todo lamentaba su corto número de efectivos, algo que achacaba a la frialdad de la población hacia la causa realista. Por ello, para fidelizar a sus tropas las convirtió en las mejor pagadas del virreinato. ${ }^{22}$ Sin embargo, las limitaciones que tanto contrariaban al comandante eran inherentes a una fuerza miliciana e improvisada. ${ }^{23}$

\section{La reunión de Calleja y Flon: la formación del Ejército del Centro}

Mientras Calleja organizaba este contingente, el recién llegado virrey Francisco Venegas (tomó posesión el 13 de septiembre) envió a Querétaro desde México una fuerza compuesta por tropas profesionales y milicianas para frenar el avance de los sublevados hacia la capital. El 29 de septiembre, 13 días después del Grito de Dolores, designó como su comandante a Manuel de Flon, que le había acompañado a México para facilitarle su instalación. $^{24}$

Manuel de Flon (Pamplona, 1745) comenzó su carrera militar en el Regimiento de Infantería de Navarra a los 16 años, y en 1780 pasó a

20 Benavides, 2016, 232.

21 Idem.

22 Cobrarían medio real diario más. Los soldados cuatro reales, aproximadamente el triple del salario habitual de un peón en la región, los cabos cuatro y medio y los sargentos seis. Parte de Calleja al virrey Venegas, San Luis Potosí, 1 de octubre de 1810, Archivo General de la Nación, México (AGN), Operaciones de Guerra (OG), 204, exp. 12.

23 La tropa estaba formada por los habitantes de la provincia, que no tenían experiencia en combate, los artesanos locales carecían de recursos y conocimientos para fabricar un arsenal, y tampoco puede achacarse a la falta de lealtad el hecho de que la mayor parte de los habitantes prefirieran seguir con sus quehaceres, en lugar de alistarse para ir a una guerra. Benavides, 2014, 290-291. 248-249.

24 Venegas puso a Flon al mando porque desconfiaba de los oficiales criollos. Alamán, 1985, 
América con el grado de teniente coronel para la campaña de Florida en el contexto de la guerra de independencia de los Estados Unidos. En 1782 se casó con María Ana Saint-Maxent, natural de Nueva Orleans, entrando a formar parte de un clan familiar de altos funcionarios emparentados con el ministro de Indias José de Gálvez. ${ }^{25}$ Esta circunstancia favoreció que en 1784 se le nombrara gobernador de Nuevo México, aunque antes de que tomara posesión le fue encargado el gobierno de la Nueva Vizcaya. Finalmente, en 1787 se le designó intendente de Puebla. ${ }^{26}$

Según las órdenes de Venegas, Flon debía acantonarse en Querétaro hasta que llegara Calleja, dejarle al mando de las tropas y regresar a Puebla. Sin embargo, el 21 de octubre abandonó la ciudad para ir al encuentro del comandante potosino que, siguiendo su propio plan, salió de San Luis el $24 .{ }^{27}$ Cuatro días después se encontraron en Dolores, formándose el denominado Ejército del Centro, del que Calleja se convirtió en general. ${ }^{28}$ En lugar de regresar a su destino, Flon se unió a la fuerza como segundo al mando. $^{29}$

Si bien procedían de regiones distintas y eran de diferentes estratos sociales (Flon era navarro y pertenecía a la nobleza titulada, mientras que Calleja era un hidalgo rural de Castilla), el general no podía haber contado con un mejor lugarteniente. Probablemente se conocieron cuando el entonces capitán Calleja llegó a Puebla en 1789 pero, aunque su paso por esta ciudad fue breve, ambos compartían trayectorias similares: eran oficiales peninsulares que tras más de 20 años de servicio llegaron a Nueva

25 María Ana era hija del coronel Gilbert Saint-Maxent, y sus tres hermanas se casaron con Luis de Unzaga, gobernador de Luisiana, Bernardo de Gálvez, virrey de México y sobrino del ministro de Indias, y con Riaño, intendente de Valladolid y luego de Guanajuato. Expediente matrimonial de Manuel de Flon, Madrid, 20 de diciembre de 1781, Archivo General Militar de Segovia (AGMS), 1ª, $1^{\mathrm{a}}, \mathrm{F}-1494$. García, 2000, 20. $17-19$.

26 Flon fue considerado uno de los intendentes más capaces de Nueva España. García, 2000,

27 En cuanto se enteró de la insurrección, Venegas le ordenó partir de inmediato a Querétaro con las milicias potosinas, pero Calleja se negó aduciendo que si abandonaba San Luis la ciudad caería en manos rebeldes, y le advirtió que seguiría tomando las medidas que considerara oportunas sin esperar su aprobación. Calleja al virrey Venegas, San Luis Potosí, 1 de octubre de 1810, AGN, OG, 91, exp. 1.

28 Convendría aclarar que Calleja tenía el rango de brigadier y en ningún momento recibió un despacho de general, simplemente, era el título con el que el resto de autoridades y sus subordinados se referían a él por ser el comandante en jefe de un ejército.

29 Calleja conocía la existencia del contingente comandado por Flon y se coordinó con su jefe para unirse en la persecución contra los rebeldes. El intendente Acevedo a Calleja, San Luis Potosí, 13 de octubre de 1810, AGN, OG, 91, exp. 25. García, 2000, 26. Posiblemente, la decisión de Flon, contraria a las órdenes que le habían dado, se debiera a su formación como militar y al deseo de venganza por la muerte de su cuñado, el intendente Riaño, durante la toma de la alhóndiga de Guanajuato. 
España, recorrieron buena parte del norte del virreinato, cumplieron con las comisiones que les fueron encargadas ganándose ascensos, y terminaron siendo importantes autoridades regionales con prestigio en todo el territorio novohispano. Además, a ambos les unía el mismo sentimiento de lealtad inquebrantable a la Corona y tenían un fuerte carácter, que pusieron de manifiesto en sus relaciones con otras autoridades. ${ }^{30}$

\section{Los cuerpos del Ejército del Centro, el bastión realista}

Autores coetáneos a la guerra afirmaron que el Ejército del Centro quedó formado por siete mil hombres, sin embargo su fuerza no superaba los seis mil. ${ }^{31} \mathrm{~A}$ lo largo del año y medio que estuvo en campaña, el número de plazas varió continuamente (bajas, reclutamientos, incorporación de otros cuerpos...), pero durante los primeros meses, cuando se produjeron las batallas de Aculco, Guanajuato y Puente Calderón contra los insurgentes, el pie de fuerza del Ejército del Centro no superó los seis mil efectivos. ${ }^{32}$

Tanto el contingente enviado por el virrey como el potosino tenían un número similar de hombres: 3.250 (53,3\%) el comandado por Flon y 2.800 $(46,7 \%)$ el de San Luis. ${ }^{33}$ Sin embargo, su composición difería notablemente en dos aspectos. En primer lugar, mientras que la fuerza potosina estaba formada prácticamente en su totalidad por milicianos, casi la mitad de los componentes de la otra fuerza eran militares profesionales (unos 1.550, el 48,5\%). Estas plazas correspondían al $1 .^{\circ}$ y $2 .^{\circ}$ batallón del Regimiento de Infantería de la Corona (950), al Regimiento de Dragones de México

30 Para el caso de Flon, algunas de sus frecuentes disputas con las autoridades poblanas y un acercamiento a su personalidad son recogidos en: Carabarín, 2005. Sobre Félix Calleja véase Benavides, 2014, 233-278.

31 Alamán, 1985, 249. Bustamante, 1828, 28.

32 Según los cálculos realizados, en enero de 1811 rondaba los 5.900 hombres. A lo largo de 1811 se agregaron: una compañía de artillería, el Regimiento Fijo de Infantería de Veracruz, el de Infantería de Nueva España y varias compañías milicianas de infantería procedentes de Puebla, Toluca, Michoacán, Guanajuato y Celaya. Posteriormente, en 1812 se unieron a este contingente diversas unidades de los regimientos provinciales de las Tres Villas, Oaxaca, Caballería de Puebla y Dragones del Príncipe, y el Regimiento de Infantería de Guanajuato. Cuerpos que formaban el Ejército del Centro durante 1811, México, 11 de febrero de 1812, AGN, Indiferente Virreinal (IV), C. 3187, exp. 23. Cuerpos que formaban el Ejército del Centro durante 1812, México, 15 de noviembre de 1812, AGN, IV, C. 3129, exp. 24.

33 Ante la imposibilidad de dar las cifras exactas del periodo de tres meses en que se desarrollaron las batallas señaladas, se ha optado por un redondeo aproximado para simplificar los datos y facilitar su comprensión. 
(420) y a un escuadrón del Regimiento de Dragones de España (180). Además se incorporaron al Ejército del Centro 1.650 milicianos pertenecientes al 1. ${ }^{\circ}$ y $2 .^{\circ}$ batallón del Regimiento de la Columna de Granaderos (1.150), al Regimiento de Dragones Provinciales de Puebla (430), y a dos compañías del Regimiento Provincial de Dragones de Querétaro (70), que se unieron a Flon durante su paso por esta ciudad. ${ }^{34}$

\section{GRÁFICO 1 \\ CUERPOS QUE FORMABAN EL EJÉRCITO DEL CENTRO}

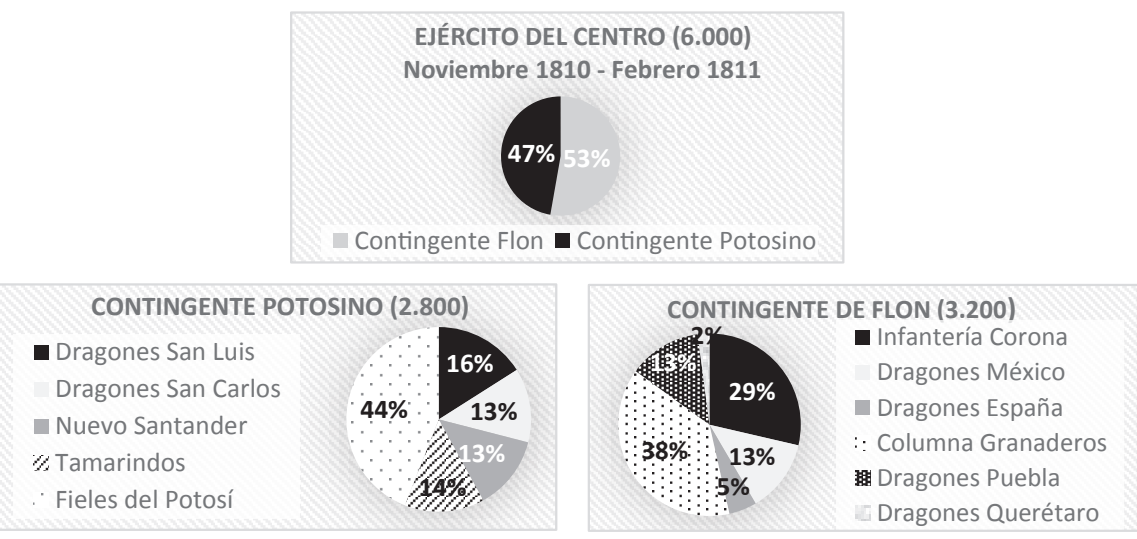

La segunda importante diferencia entre ambos contingentes era que el potosino estaba formado fundamentalmente por una tropa montada (en torno a 2.400 hombres, un $86 \%$ ), pero el comandado por Flon era en su mayor parte de infantería (unos 2.150 hombres, el $67 \%$ ). ${ }^{35}$ Debido a esta circunstancia la suma de ambas fuerzas guardaba un cierto equilibrio entre las dos armas, caballería y dragones por un lado e infantería por otro.

34 Revista del Regimiento de Dragones de México, México, 30 de agosto de 1810, AGN, IV, C. 3021, exp. 1. Revista del $1 .^{\circ}$ y $2 .^{\circ}$ batallón de la Columna de Granaderos, Lagos, 3 de enero de 1811, AGN, IV, C. 3273, exp. 3. Revista del Escuadrón de Dragones de España, León, 16 de septiembre de 1811, AGN, IV, C. 4242, exp. 10. Antigüedad, hojas de servicio y lista de revista del Regimiento Provincial de Dragones de Puebla, Puebla, 30 de diciembre de 1806, AGN, IV, C. 4901. Lista del $1 .^{\circ}$ y 2. ${ }^{\circ}$ batallón del Regimiento de Infantería de la Corona, México, 6 de junio de 1810, AGN, IV, C. 5934.

35 Idem. Lista de los regimientos provinciales de San Luis y San Carlos, del Cuerpo de Lanceros del Potosí, del Cuerpo de Patriotas de San Luis y del Cuerpo de Caballería de Frontera del Nuevo Santander, Lagos, 3 de enero de 1811, AGN, IV, C. 3824, exp. 1. 
En definitiva, el Ejército del Centro reunido en Dolores a finales de octubre de 1810, que luchó y derrotó a los insurgentes en Aculco, Guanajuato y Puente Calderón, estaba formado por tropas de once cuerpos, ocho milicianos y tres veteranos, procedentes de cuatro regiones (San Luis, Querétaro, México y Puebla). La mayoría de las plazas eran montadas (unos 3.450 hombres), aunque había un componente importante de infantería y, si bien contaba con unos 1.550 militares, era una fuerza mayoritariamente miliciana (74\%), es decir, formada por hombres con cierta instrucción militar pero que no eran profesionales.

\section{GRÁFICO 2}

\section{COMPOSICIÓN DEL EJÉRCITO DEL CENTRO}
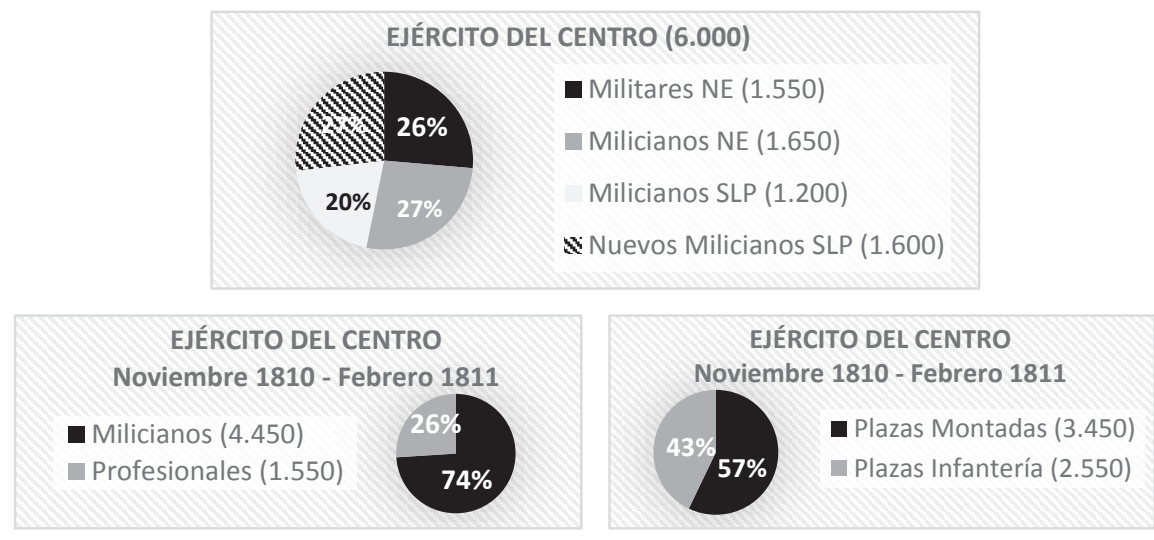

Calleja se mostraba pesimista con respecto a su ejército, porque carecía de artillería fiable y las armas de fuego eran escasas, porque sus tropas no tenían experiencia en campaña y una gran parte apenas estaban instruidas, pero sobre todo porque, en el mejor de los casos, los insurgentes triplicaban su pie de fuerza. ${ }^{36}$ Pero habría que considerar que estas quejas provenían del jefe de un ejército antes de emprender una campaña, al que

36 Según los informes que le habían pasado (algunos más fiables que otros), los rebeldes contaban con unos 15.000 hombres y este número aumentaba en cada población por la que pasaban. Parte de Calleja al virrey Venegas, San Luis Potosí, 1 de octubre de 1810, AGN, OG, 204, exp. 12. Archer, 1997, 128 y 129. 
en cualquier caso le resultarían insuficientes las tropas, armas y recursos de los que pudiera disponer. El Ejército del Centro, teniendo en cuenta que se formó en apenas un mes, con tropas de distinto origen y diversa índole, y que el sistema defensivo novohispano estaba diseñado como preventivo ante un posible ataque externo, era la mejor fuerza que podía formarse en el virreinato. Además, las carencias que contrariaban al general no eran tan determinantes como suponía porque el enemigo, si bien más numeroso, sufría mayores limitaciones.

\section{Los hombres que luchaban por el rey}

Una vez expuesta la formación del Ejército del Centro y analizadas las principales características de los cuerpos que lo componían, se realizará una aproximación a los hombres que formaban parte del mismo. La principal dificultad para el estudio de la composición social de esta fuerza es la escasez de fuentes. Aun así, a pesar de las carencias documentales, podemos arrojar algunos datos fiables u orientativos cuando menos.

\section{La oficialidad}

El número de oficiales del Ejército del Centro era de 378. Tan solo había 95 militares de carrera y el resto eran milicianos, 70 de ellos sin ninguna experiencia previa en el servicio anterior a septiembre de 1810 .

GRÁFICO 3

CLASES DE LA OFICIALIDAD DEL EJÉRCITO DEL CENTRO

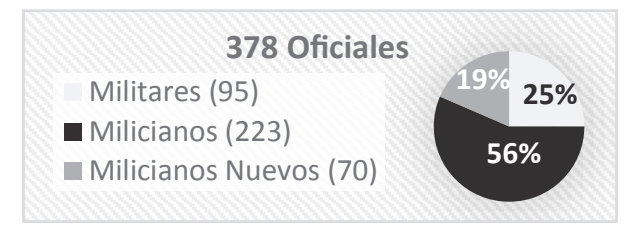

Según la información consultada, que aporta datos sobre algo más de la mitad de la oficialidad, los oficiales de origen americano representaban el 
$65 \%$ del total. ${ }^{37}$ La mayoría eran vecinos de la provincia potosina, de la de Puebla y de la ciudad de México, las tres regiones de donde procedía el grueso de las fuerzas, aunque también estaban representadas otras provincias del virreinato. Entre los oficiales peninsulares predominaban los originarios de las zonas con mayor presencia en el virreinato: vasco-navarros, montañeses, andaluces y castellanos, que eran el $90 \%$ del total de europeos. ${ }^{38}$

\section{GRÁFICO 4}

\section{ORIGEN DE LA OFICIALIDAD DEL EJÉRCITO DEL CENTRO ${ }^{39}$}
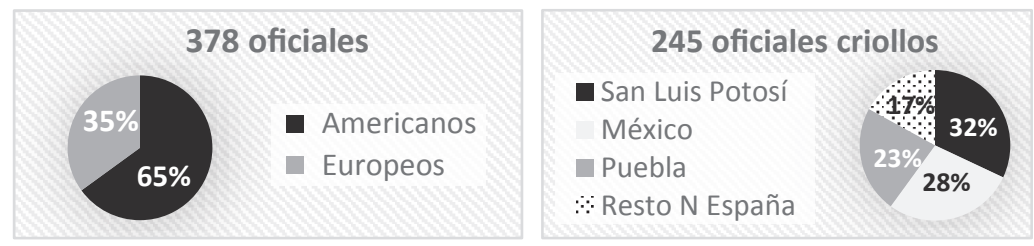

Las nuevas incorporaciones formaban parte del contingente potosino, que según los datos consultados (unos dos tercios del total), estaba compuesto por 163 oficiales, el $43 \%$ de la totalidad. ${ }^{40}$ Antes del inicio de la guerra, la oficialidad potosina estaba formada predominantemente por hombres maduros, con varios años de servicio y de origen peninsular $(70 \%) .^{41}$ Sin embargo el estallido insurgente transformó la composición social de este

37 Los datos que se presentan a continuación se han obtenido sobre los 196 oficiales de los que se ha localizado información (52\%). Las fuentes son de diversas fechas en torno a 1810, por lo que no es posible aportar cifras exactas, aunque la información permite extraer algunas conclusiones fiables.

38 Hojas de servicio del Regimiento de Dragones de España, México, 30 de diciembre de 1808, AGN, Indiferente de Guerra (IG), 360. Hojas de servicio del Regimiento de San Carlos, Tula, 30 de diciembre de 1812, AGN, IG, 73. Hojas de servicio del Regimiento de Dragones Fieles del Potosí, México, 31 de diciembre de 1813, AGN, IG, 121ª . Hojas de servicio del Regimiento de San Luis, 30 de diciembre de 1812, AGN, IG, 133b. Hojas de servicio del batallón de Infantería de San Luis, 30 de diciembre de 1812, AGN, IG, 186a. Hojas de servicio del Regimiento de Infantería de la Corona, México, 30 de diciembre de 1806, AGN, IV, C. 6020, exp. 59. Hojas de servicio del Regimiento de Infantería de la Corona, México, 30 de diciembre de 1812, AGN, IV, C. 4691, exps. 1,4 y 6. Hojas de servicio de las milicias provinciales del Nuevo Santander, Valles, 30 de diciembre de 1806, AGN, Provincias Internas, 263, exp. 1.

39 Datos extrapolados de los resultados obtenidos sobre 196 oficiales, el $52 \%$ del total.

40 Disponemos de datos concretos de 108 (66\%).

41 Aproximadamente la mitad de los oficiales eran vasco-navarros y montañeses, el $60 \%$ tenían más de 40 años, tan solo el $30 \%$ estaban solteros y el 70 \% llevaban sirviendo más de diez años. Benavides, 2014, 334-335. 
grupo, tanto por el establecimiento de los nuevos cuerpos como porque un buen número de oficiales renunciaron al no estar en condiciones de realizar el servicio en campaña ${ }^{42}$ Los empleos vacantes se cubrieron con ascensos internos, lo que facilitó el acceso a la oficialidad de algunos suboficiales, y con la incorporación de varios medianos propietarios, mineros y comerciantes, que acudieron a la llamada de Calleja con un grupo de dependientes. Casi todos eran criollos por lo que, en suma, la oficialidad del contingente potosino era mayoritariamente de origen americano (61\%). Asimismo, la recluta de octubre de 1810 supuso un rejuvenecimiento de la oficialidad (23\% era menor de 25 años) y un incremento de la cifra de solteros (del 30 al $52 \%$ ), ya que la mayoría de los hombres que ocuparon estos empleos eran jóvenes y sin ataduras familiares. ${ }^{43}$

\section{GRÁFICO 5 \\ EVOLUCIÓN DEL ORIGEN DE LOS OFICIALES DE LOS CUERPOS MILICIANOS POTOSINOS}
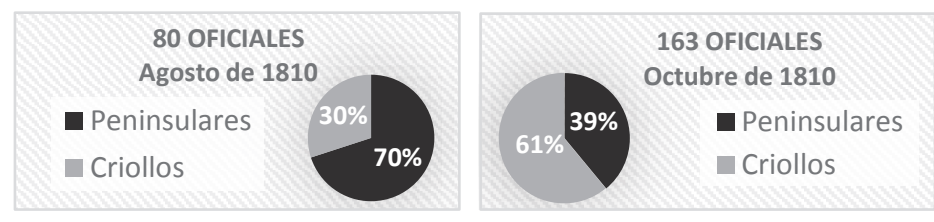

En cuanto a los oficiales profesionales, solo se ha localizado información sobre el Regimiento de Infantería de la Corona y el de Dragones de España, por lo que los datos se refieren a la mitad del total de la oficialidad profesional (47\%). Cabría señalar el claro predominio de los novohispanos $(68 \%)$, la mitad de ellos procedentes de la ciudad de México. La gran

42 Renunciaron en torno a un $35 \%$ de los oficiales de los regimientos provinciales, lo que unido a la creación de las nuevas plazas, provocó la necesidad de designar a unos 90 oficiales. Idem.

43 La mayoría eran potosinos (42\%). Entre los peninsulares, como venía sucediendo, destacaba la presencia de vasco-navarros $(20 \%)$ y de montañeses $(10 \%)$, y entre los criollos también habría que mencionar a los procedentes de Zacatecas (la mayoría de Sierra de Pinos) y de Guanajuato. Hojas de servicio del Regimiento de San Carlos, Tula, 30 de diciembre de 1812, AGN, IG, 73. Hojas de servicio del Regimiento de Dragones Fieles del Potosí, México, 31 de diciembre de 1813, AGN, IG, 121a. Hojas de servicio del Regimiento de San Luis, 30 de diciembre de 1812, AGN, IG, 133b. Hojas de servicio del batallón de Infantería de San Luis, 30 de diciembre de 1812, AGN, IG, 186a. Hojas de servicio de las milicias provinciales del Nuevo Santander, Valles, 30 de diciembre de 1806, AGN, Provincias Internas, 263 , exp. 1. 
mayoría eran solteros ( $81 \%$ ), de mediana edad, entre 25 y 40 años (64 \%), y con al menos una década de experiencia en el servicio ( $72 \%) .{ }^{44}$ Del resto de oficiales del contingente enviado por el virrey, los milicianos, solo es posible aportar datos del Regimiento Provincial de Dragones de Puebla. Se trataba de una oficialidad predominantemente novohispana (70\%) y que, al igual que las milicias potosinas antes del estallido insurgente, poseía una larga trayectoria en la milicia (el $75 \%$ llevaban más de diez años de servicio) y una media de edad elevada (solo el $12 \%$ tenían menos de 30 años), aunque es posible que, como en San Luis, en 1810 se produjera un rejuvenecimiento de la oficialidad. ${ }^{45}$

Sin embargo, aunque el predominio de los oficiales criollos parece evidente, los peninsulares siguieron siendo mayoría entre los rangos más elevados. ${ }^{46}$ El general del ejército, su ayudante personal, el teniente coronel Bernardo Villamil, ${ }^{47}$ y su lugarteniente, el coronel Manuel de Flon, habían nacido en España, al igual que ocho de los once comandantes de los cuerpos que formaban el Ejército del Centro: 1) Regimiento de San Luis: sargento mayor José Tovar (Andalucía); 2) Regimiento de San Carlos: coronel Ramón Cevallos (montañés); 3) Caballería del Nuevo Santander: Manuel Díaz de Solórzano (montañés); 4) Fieles del Potosí: teniente coronel Pedro Meneso (montañés); 5) Dragones de México: coronel Miguel José de Emparán (Guipúzcoa); 6) Columna de Granaderos: capitán Saturnino Sama-

44 Entre los peninsulares la mayoría eran andaluces. A modo de anécdota, señalar la presencia de un oficial procedente de Guayaquil, otro de Manila y otro del Piamonte italiano. Hojas de servicio del Regimiento de Dragones de España, México, 30 de diciembre de 1808, AGN, IG, 360a. Hojas de servicio del Regimiento de Infantería de la Corona, México, 30 de diciembre de 1806, AGN, IV, C. 6020, exp. 59. Hojas de servicio del Regimiento de Infantería de la Corona, México, 30 de diciembre de 1812, AGN, IV, C. 4691, exps. 1, 4 y 6.

45 Hojas de servicio del Regimiento de Dragones de Puebla, Puebla, 30 de diciembre de 1806, AGN, IV, C. 4901 , exps. 33 y 34.

46 En el caso de los cuerpos potosinos, el $62 \%$ de los altos mandos (coroneles, tenientes coroneles y capitanes) eran europeos, aunque su proporción descendió (antes el $85 \%$ ). Hojas de servicio del Regimiento de San Carlos, Tula, 30 de diciembre de 1812, AGN, IG, 73. Hojas de servicio del Regimiento de Dragones Fieles del Potosí, México, 31 de diciembre de 1813, AGN, IG, 121a. Hojas de servicio del Regimiento de San Luis, 30 de diciembre de 1812, AGN, IG, 133b. Hojas de servicio del batallón de Infantería de San Luis, 30 de diciembre de 1812, AGN, IG, 186a.

47 Nació en el Campo de Gibraltar (Cádiz) y llegó a Nueva España en 1790, con 13 años, ya que su padre había sido agregado como capitán al Regimiento de México. Allí comenzó su carrera militar como cadete. En 1808 ascendió a teniente coronel y fue designado ayudante del comandante de la $10^{a}$ brigada. En San Luis entró a formar parte de la élite al casarse con María Josefa de la Gándara, prima de Francisca, la esposa de Calleja, en 1810. Información y licencia de pasajero a Indias de Antonio Villamil y su familia, Cádiz, 28 de enero de 1790, Archivo General de Indias, Sevilla (AGI), Contratación, 5535, N. 10. Expediente matrimonial de Bernardo Villamil, San Luis Potosí, 1810-1811, AGMS, $1^{\mathrm{a}}, 1^{\mathrm{a}}$, F-364. Hoja de servicio de Bernardo Villamil, México, 30 de octubre de 1819, AGMS, 1ª $1^{\text {a }}$, B-2722. 
niego (Navarra); 7) Dragones de Querétaro: teniente coronel Manuel Pastor (Navarra); y 8) Dragones de Puebla: coronel Diego García Conde y sargento mayor teniente coronel Miguel del Campo (Cataluña). Todos tenían en común, además de su origen peninsular, una larga trayectoria en el ejército y que en 1810 llevaban más de 20 años sirviendo en Nueva España. ${ }^{48}$

Tan solo estaban bajo las órdenes de criollos: 1) el batallón de Infantería de San Luis, que comandaba Juan Nepomuceno Oviedo (San Miguel, Guanajuato); 2) el escuadrón del Regimiento de Dragones de España, al mando del capitán Francisco de Arroyabe (Guatemala); y 3) el Regimiento de Infantería de la Corona, cuyo coronel, Nicolás de Iberri, era de Pensacola, y el sargento mayor, José María de Villalba, de Veracruz. ${ }^{49}$

Además, a pesar de ser una fuerza eminentemente miliciana, los mandos que dirigían los cuerpos que formaban el Ejército del Centro eran sobre todo militares profesionales. Esta circunstancia se explicaría porque los oficiales veteranos tenían un mayor grado de disciplina e instrucción y experiencia en el servicio en campaña.

\section{GRÁFICO 6}

\section{MANDOS DEL EJÉRCITO DEL CENTRO}
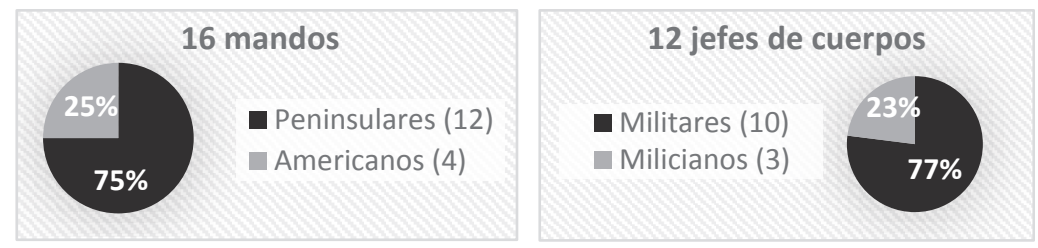

48 Nombramiento de Ramón de Cevallos como coronel del Regimiento de San Carlos, El Escorial, 26 de diciembre de 1807, AGMS, 1ª $1^{\text {a }}$, C-2470. Hoja de servicio del teniente coronel Miguel del Campo, México, 30 de octubre de 1816, AGMS, 1ª $1^{\text {a }}$, C-797. Solicitud de ascenso a teniente coronel del capitán Manuel Díaz Solórzano, Rioverde, 1 de mayo de 1810, AGMS, $1^{\text {a }}, 1^{\text {a }}$, D-626. Hoja de servicio de Miguel José Emparan, Madrid, 1 de marzo de 1817, AGMS, $1^{\mathrm{a}}, 1^{\mathrm{a}}$, E-325. Hoja de servicio de Diego García Conde, México, 30 de agosto de 1818, AGMS, 1ª $1^{\mathrm{a}}$, G-776. Hoja de servicio de Pedro Meneso, Madrid, 13 de agosto de 1820, AGMS, $1^{\text {a }}, 1^{\text {a }}$, M-2905. Solicitud de ascenso a coronel de Manuel Pastor, Querétaro, 15 de julio de 1805, AGMS, $1^{\text {a }}, 1^{\text {a }}$, P-704. Solicitud de aumento de pensión de retiro de Saturnino Samaniego, Madrid y Sevilla, 1823-1836, AGMS, $1^{\text {a }}, 1^{\text {a }}$, S-566. Hojas de servicio del Regimiento de San Luis, 30 de diciembre de 1812, AGN, IG, 133b.

49 Expediente matrimonial del capitán Francisco Arroyabe, Madrid, 28 de abril de 1807 , AGMS, $1^{\text {a }}, 1^{\text {a }}$, A-2497. Expediente matrimonial del capitán José María de Villalba, Veracruz, 24 de noviembre de 1800, AGMS, 1ª $1^{\text {a }}$, B-2671. Expediente matrimonial del teniente coronel Nicolás Iberri, Madrid, 2 de mayo de 1807, AGMS, 1ª $1^{\text {a }}$, I-120. Hojas de servicio del Regimiento de San Carlos, Charcas, 31 de diciembre de 1796, AGS, SGU, 7273, exp. 2. 


\section{La tropa}

La carencia de fuentes documentales anteriormente señalada es todavía mayor a la hora de analizar el sector más bajo y numeroso del escalafón, la tropa. Aun así, es posible dar a conocer algunos datos fundamentados. El número total de soldados del Ejército del Centro rondaba los 4.870 hombres, el $46 \%$ perteneciente al contingente potosino y el $54 \%$ restante al comandado por Flon. Tan solo el $28 \%$, unos 1.300, eran militares profesionales. Cabría señalar que no se contabiliza a los suboficiales, unos 750 cabos y sargentos, porque los datos para este sector, diferente a la tropa dentro del escalafón (aunque no tanto sociológicamente), provienen de otras hojas de servicio que apenas se conservan.

\section{GRÁFICO 7}

TROPA DEL EJÉRCITO DEL CENTRO

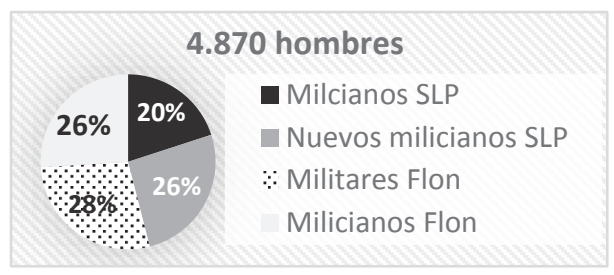

Sobre los soldados de la fuerza formada por Calleja en la Pila, solo contamos con algunas referencias tangenciales e indirectas, gracias a las cuales es posible presentar un perfil del miliciano de a pie potosino que formó parte del Ejército del Centro durante los primeros meses de la guerra. Su número rondaba los 2.250 hombres, la mayoría, unos 1.300, voluntarios alistados durante el mes de octubre.

Aunque no se puedan ofrecer datos concretos, la mayor parte eran peones de las haciendas del altiplano potosino (San Luis, Santa María del Río, Guadalcázar, Venado y Charcas). ${ }^{50}$ El resto, que provenía de diferentes

50 Además de las siete compañías de los regimientos de San Luis y San Carlos formadas en haciendas (unos 200 hombres), y de los hombres procedentes de la hacienda de Bocas, que eran la mayor parte de los Tamarindos, Juan Moncada, marqués del Jaral y conde de San Mateo, formó una tropa con sus empleados, y otros hacendados enviaron a sus peones al campo de la Pila: 30 desde la hacienda de Espíritu Santo, 80 del Pozo del Carmen y 38 de Guanamé. Monroy y Calvillo, 1997, 144-146. Bernal, $2005,162$. 
poblaciones de la región, también estaba dedicado a tareas agro-ganaderas. ${ }^{51}$ En cuanto a la presencia de milicianos del oriente de la provincia (Valles y Rioverde), además de los casi 300 hombres del Cuerpo de Frontera del Nuevo Santander, fueron enviadas por los subdelegados algunas partidas, aunque no muy numerosas. ${ }^{52} \mathrm{El}$ componente indígena, si bien presente, era escaso ya que, aunque varios pueblos indios mandaron hombres, la mayoría no fueron alistados porque los oficiales consideraban que no reunían las condiciones necesarias. ${ }^{53}$

\section{GRÁFICO 8 \\ ORIGEN DE LA TROPA DEL CONTINGENTE POTOSINO DEL EJÉRCITO DEL CENTRO}

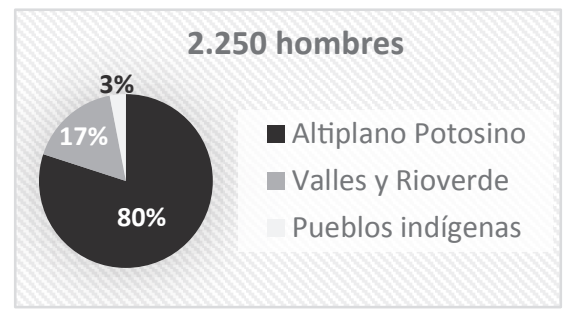

Para el resto de cuerpos, la fuente que más datos aporta sobre la tropa son las hojas de filiación, unos documentos redactados por los reclutadores que cada hombre firmaba al alistarse ${ }^{54}$ Las filiaciones consultadas han aportado información sobre casi mil soldados que participaron en la

51 Algunos de ellos posiblemente también se dedicasen de forma ocasional al laboreo de minas.

52 En estos contingentes estaban algunos oficiales que tuvieron un papel protagonista en los primeros años del México independiente, como Miguel Barragán, Manuel Gómez Pedraza o Anastasio Bustamante. El subdelegado de Valles al intendente Acevedo, Valle del Maíz, 8 de octubre de 1810, AGN, OG, 91, exp. 33. El intendente Acevedo a Calleja, San Luis Potosí, 17 de octubre de 1810, AGN, OG, exp. 41. Rangel, 2007, 75.

53 El barrio de Tlaxcalilla aportó 200 hombres y el gobernador de Mexquitic envió a la Pila otros 300. Juan Gregorio Juárez al intendente Acevedo, San Luis Potosí, 8 de octubre de 1810, AGN, OG, 91, exp. 11. Orden de Calleja al capitán Cortina, La Pila, 24 de octubre de 1810, AGN, OG, exp. 57. Ortiz, 2014, 110 y 111.

54 Son documentos de identidad en los que aparece el cuerpo y la compañía en la que quedaba destinado el recluta, la fecha y el lugar del alistamiento y el tiempo por el que se alistaba. Además incluían una serie de datos personales: nombre, lugar de nacimiento y vecindario, edad, profesión (anterior al alistamiento), raza, estado civil y una somera descripción física. También permiten saber si el recluta era analfabeto o no, dependiendo de si firmaba el documento o marcaba una cruz. 
primera campaña del Ejército del Centro, destinados en cinco de los once cuerpos que lo conformaban, tres profesionales (Infantería de la Corona, Dragones de México y Dragones de España) y dos milicianos (Columna de Granaderos y Dragones Provinciales de Puebla). Sin embargo, las aportaciones sobre estos últimos regimientos son demasiado escasas para poder obtener conclusiones fiables (inferiores al $8 \%$ del pie de fuerza), por lo que la presentación de los resultados se limita a la tropa veterana del contingente comandado por Flon, unos 1.330 hombres. ${ }^{55}$

Casi la totalidad de los soldados procedían de las regiones de México, Puebla, Michoacán y Querétaro (84\%), estaban avecindados en núcleos urbanos $(72 \%)$ y eran solteros $(92 \%) .{ }^{56}$ Antes de alistarse, el $58 \%$, se dedicaban a diversos oficios (zapateros, sastres, sombrereros, albañiles, tejedores, barberos, neveros, veleros, carpinteros, pintores, herreros...), aunque también había un porcentaje importante de labradores y arrieros. ${ }^{57}$ Para 1810, el $58 \%$ estaban en un rango de edad de los 20 a los 35 años, aunque el componente de menores de 20 también tenía una importante representación (31\%). En cuanto al color, la presencia de blancos era ligeramente superior a la de mestizos (55 y $45 \%$, respectivamente). Su grado de alfabetización era elevado, el $52 \%$, algo que tendría su explicación en la importante presencia de soldados procedentes de núcleos urbanos y dedicados a oficios, para cuyo desempeño tuvieron que aprender las operaciones básicas, a leer y a escribir. ${ }^{58}$

55 Este estudio se basa en la información recogida en 960 filiaciones, que representan el $72 \%$ del total de la tropa veterana del Ejército del Centro. Filiaciones del Regimiento de Dragones de México, México, 1811, AGN, IV, C. 1849, exp. 6. Filiaciones del Regimiento de Infantería de la Corona, México, 1801, AGN, IV, C. 2824, exp. 22. Filiaciones del Regimiento de Dragones de México, Querétaro, julio de 1809, AGN, IV, C. 3021, exp. 1. Filiaciones del Regimiento de Infantería de la Corona, México, 1806, AGN, IV, C. 4684, exp. 4. Filiaciones del Regimiento de Dragones de México, México, 1810, AGN, IV, C. 4939, exp. 1. Filiaciones del Regimiento de Dragones de México, México, Puebla y San Luis Potosí, 1809, AGN, IV, C. 5010, exp. 1. Filiaciones del Regimiento de Infantería de la Corona, México, 1809, AGN, IV, C. 5156, exp. 17. Filiaciones del Regimiento de Dragones de México, México, 1811, AGN, IV, C. 5508, exp. 20. Filiaciones del Regimiento de Infantería de la Corona, México, 18071808, AGN, IV, C. 5516, exp. 1. Filiaciones del Regimiento de Infantería de la Corona, Jalapa, diciembre de 1808, AGN, IV, C. 5605, exp. 48. Filiaciones del Regimiento de la Corona, México, Guadalajara, Michoacán, Puebla y San Luis Potosí, 1809, AGN, IV, C. 5916, exp. 4. Filiaciones del Regimiento de Dragones de México, México, noviembre de 1810, AGN, IV, C. 5921, exp. 23. Filiaciones del Regimiento de Infantería de la Corona, 1809-1810, AGN, IV, C. 5934, exps. 2, 4, 5, 13.

56 También los había procedentes de Guanajuato, Tlaxcala, Veracruz, Guadalajara, San Luis Potosí y Oaxaca, pero entre todas estas regiones sumaban el $8 \%$. Además, cabría mencionar la presencia de siete españoles, tres de Luisiana y un filipino. Idem.

57 La presencia de estudiantes, comerciantes, escribientes, mineros y algunos sin oficio era testimonial.

58 Sobre esta cuestión véase Pérez-Toledo, 1996. 
Estos datos sobre la tropa profesional, alistada poco tiempo antes del comienzo de la guerra en 1810, apuntan a que el virreinato y en especial los núcleos urbanos del centro sufrían una situación de crisis económica, en buena parte debida a la Consolidación de los Vales Reales (1806-1808). A consecuencia de esta situación, un importante número de jóvenes aprendices del comercio y diversos oficios, ante la imposibilidad de progresar y labrarse un futuro con sus empleos, veían en el ejército la posibilidad de ganarse la vida..$^{59}$

\section{GRÁFICO 9}

\section{CARACTERÍSTICAS DE LA TROPA PROFESIONAL DEL EJÉRCITO DEL CENTRO (1.330 HOMBRES)}

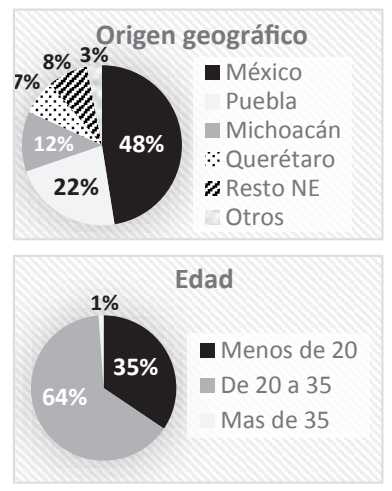

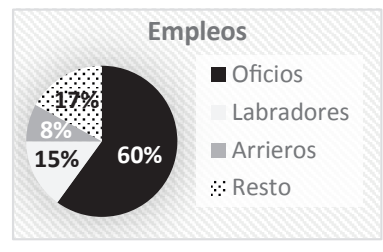

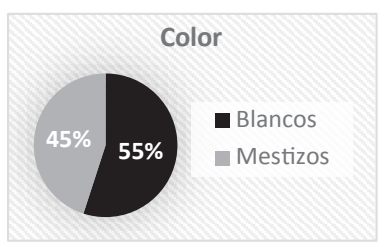

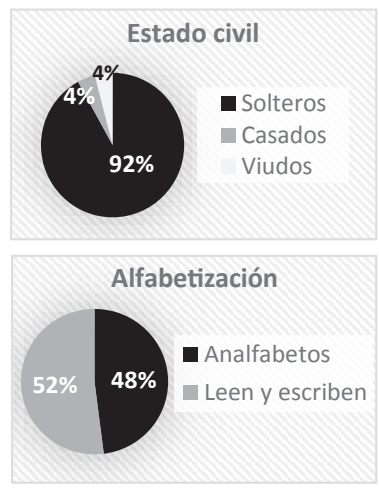

Cruzando estos datos con los del contingente potosino y considerando que la tropa miliciana del Regimiento de Dragones de Puebla y del de Querétaro procedía casi en su totalidad de esas regiones, se puede presentar la siguiente estimación del origen del total de la tropa del Ejército del Centro.

59 Ante la acuciante necesidad de la Corona de obtener nuevas fuentes de financiación, en diciembre de 1804 se aprobó la Consolidación de Vales Reales, que en México se aplicó de forma rigurosa porque el virrey Iturrigaray era un protegido de Godoy, el impulsor de la medida. Las instituciones religiosas, principales entidades crediticias del momento, fueron obligadas a entregar en las Cajas de Amortización el valor líquido de sus bienes a cambio de un $5 \%$ de interés, que sería pagado por la real hacienda. El $60 \%$ del dinero procedía de préstamos que los deudores se vieron obligados a devolver, perdiendo una buena parte o casi todos sus medios de vida, lo que provocó que la economía novohispana se resintiera profundamente. Von Wobeser, 2003, 74-81. 
GRÁFICO 10

ORIGEN GEOGRÁFICO DE LA TROPA DEL EJÉRCITO DEL CENTRO (APROX.) ${ }^{60}$

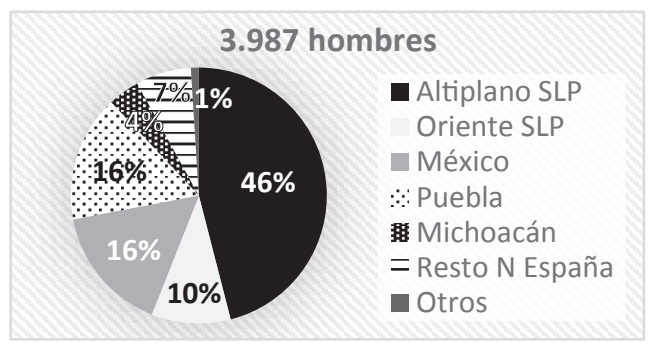

\section{La campaña victoriosa}

Una vez reunido y formado el Ejército del Centro en Dolores el 28 de octubre partió hacia Querétaro, donde llevó a cabo una actuación que serviría de modelo para el resto de poblaciones por las que pasaría durante la campaña: dura y corta represión contra los rebeldes y posterior publicación de un bando de indulto. ${ }^{61}$ Después se enfrentó y derrotó a los insurgentes en Aculco y se encaminó hacia Guanajuato, ciudad que tomó el 25 de noviembre. ${ }^{62}$ A comienzos de diciembre inició su marcha sobre Guadalajara, donde se encontraban Hidalgo y Allende, y el 17 de enero venció a la mayor fuerza de los rebeldes en el Puente Calderón. Esta batalla, en la que perdió la vida Manuel de Flon, dejó a la insurgencia herida de muerte, a pesar de que los cabecillas lograron escapar. ${ }^{63}$

El 5 de marzo, las tropas realistas regresaron a San Luis, donde llevaron a cabo una dura represión. Dos semanas después los líderes insurgentes

60 Faltarían por incluirse los 900 efectivos de la Columna de Granaderos, de los que no se han localizado datos concretos para este periodo.

61 Fundamentalmente, estos bandos contenían tres puntos: indulto a los que depusiesen las armas y perdón para los cabecillas que entregasen a otro líder rebelde, prohibición de reuniones y abandonar la ciudad y advertencia de que una nueva sublevación representaría un duro castigo. Bando de Calleja contra la insurrección, Querétaro, 4 de noviembre de 1810, AGN, OG, 170. Para el caso de Guanajuato, se señalan varios ejemplos de esta actuación en Bernal, 2014, 353-354.

62 Fue a partir de entonces, gracias a los efectos incautados al enemigo tras su huida, cuando el Ejército del Centro pudo contar con una artillería fiable. Informe de Martín García Loygorri al Ministerio de Guerra, Cádiz, 24 de febrero de 1811, Archivo General Militar de Madrid (AGMM), Nueva España, 5372, 11.

63 Para más detalles sobre esta importante batalla, así como su utilización propagandística posterior, véase: Olveda, 2011, 163-177. Vázquez, 2010. 
fueron capturados en las Norias de Baján (Coahuila). La mayoría acabaron fusilados, pero la guerra no había terminado. La presencia de partidas rebeldes por casi todo el virreinato interrumpía las comunicaciones, el comercio y los envíos de plata, así que en abril de 1811 el Ejército del Centro inició una nueva campaña. Durante los siguientes nueve meses persiguió y reprimió a los insurgentes por Zacatecas, Aguascalientes y el Bajío, ${ }^{64}$ y en enero de 1812 tomó a sangre y fuego Zitácuaro (Michoacán), donde los rebeldes habían establecido una junta. ${ }^{65}$

A comienzos de febrero, tras una agria polémica entre Calleja y el virrey, el contingente realista fue recibido con honores por la población de México. Ambos personajes, enemistados desde el comienzo de la guerra, ejemplificaban las diferencias existentes entre los militares enviados desde la Península y los que estaban asentados en el virreinato. ${ }^{66} \mathrm{La}$ altanería y la mentalidad colonialista de los oficiales recién llegados de Europa contrastaban con la actitud de los que habían hecho carrera en América, unidos al territorio por lazos materiales y personales. ${ }^{67}$ Venegas, que había participado en la victoria de Bailén sobre el ejército napoleónico, menospreciaba a Calleja porque se relacionaba con criollos y sus méritos no iban más allá del cumplimiento diligente de algunas comisiones. Por su parte, este consideraba al virrey un recién llegado cuyo desconocimiento de la realidad novohispana imposibilitaba acabar con la insurgencia. ${ }^{68}$

Después del homenaje, que se prolongó una semana, el Ejército del Centro partió a Cuautla, donde se había atrincherado el caudillo insurgente Morelos. Comenzó entonces un duro asedio en el que las tropas realistas

64 Bustamante, 1828, 108-118.

65 El objetivo era demostrar a la población las consecuencias de desafiar la autoridad del rey. Parte sobre la acción de Zitácuaro, Zitácuaro, 6 de enero de 1812, AGMM, Nueva España, 5372, 16. Archer, 2005, 245-246.

66 Tras el estallido insurgente Calleja hizo caso omiso de las órdenes del virrey y siguió su propio plan (ver nota 26). Posteriormente, Venegas se negó a reconocer los méritos de sus tropas tras vencer en tres ocasiones a los insurgentes, lo que motivó una respuesta airada y una amenaza velada por parte del general, ante lo que el virrey se vio obligado a conceder a los miembros del Ejército del Centro un escudo honorífico con el emblema «Venció en Aculco, Guanajuato y Calderón». Bustamante, $1828,85-93$.

$67 \mathrm{Al}$ entrar en Guadalajara después de vencer en Puente Calderón, Calleja publicó un bando dirigido a los habitantes en el que resaltaba que, después de 20 años viviendo en Nueva España, consideraba América su hogar por los lazos familiares y afectivos que le unían a esa tierra. Ferguson, 1973, 107-108.

68 La táctica implementada por Venegas, basada en la fuerza y en castigos ejemplares, solo consiguió alimentar el resentimiento de los partidarios de la independencia. Durante la segunda campaña del Ejército del Centro, Calleja comprendió la necesidad de modificar la estrategia para ganar la guerra. Benavides, 2014, 328-330. 
sufrieron numerosas bajas por los problemas de aprovisionamiento y enfermedades. Tras 72 días, el 2 de mayo Morelos consiguió escapar, tras lo cual Calleja, gravemente enfermo (padecía dolores de estómago crónicos), se retiró a México y presentó su renuncia. El virrey Venegas, preocupado ante la creciente popularidad del general y aprovechando que los insurgentes no contaban con una gran fuerza, decidió disolver el Ejército del Centro. ${ }^{69}$

MAPA 2

\section{CAMPAÑAS DEL EJÉRCITO DEL CENTRO}

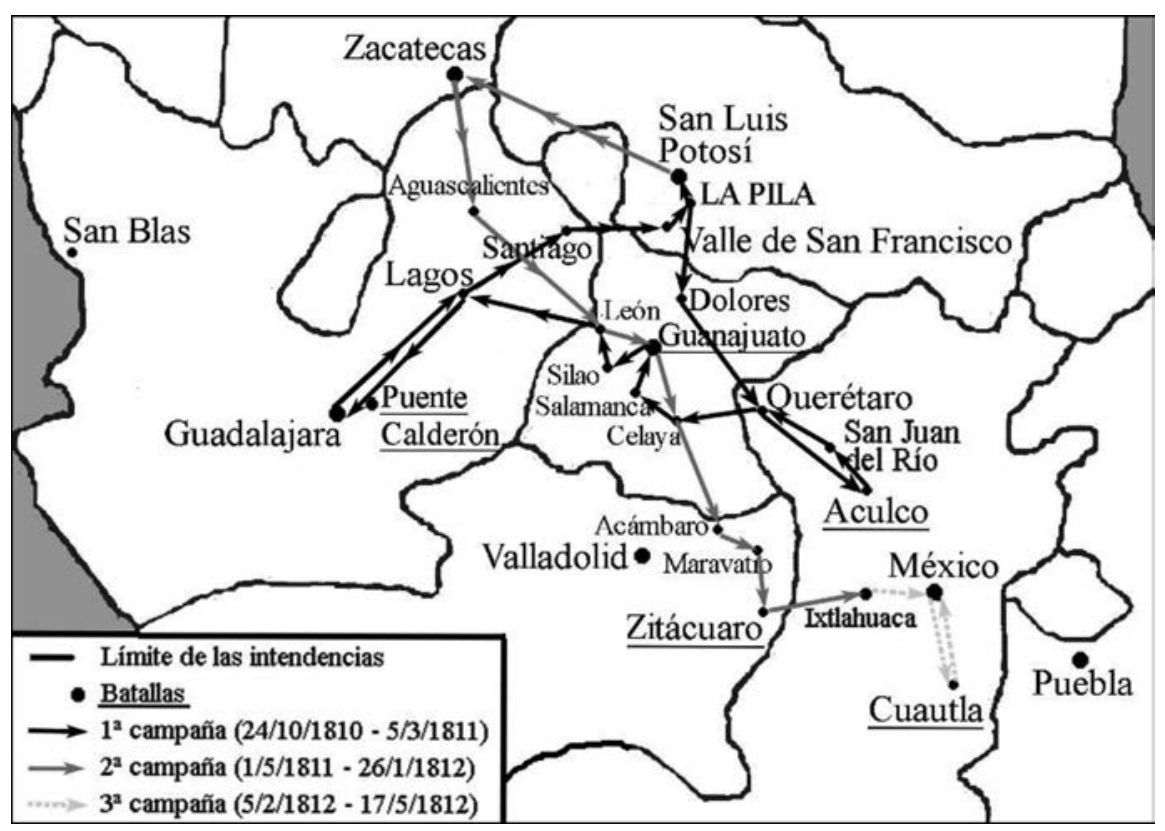

Elaboración propia.

La fama de las victorias de esta fuerza, que había logrado mantener bajo el dominio del rey la Nueva España, llegó hasta Cádiz propiciando la designación de su general como virrey, tras una «lucha política» entre las camarillas

69 Los diferentes cuerpos que lo formaban se insertaron en otras nuevas unidades por separado. Núñez, 1950, 177-194. Hernández, 2011, 43. 
de partidarios de Calleja y Venegas. ${ }^{70}$ Instalado en el palacio virreinal desde marzo de 1813, Calleja aplicó una estrategia de guerra fundamentada en la máxima que regía el sistema defensivo del imperio desde finales del siglo XVIII: la defensa de América debía recaer principalmente sobre sus habitantes. El «Plan Calleja» movilizó a unos 85.000 hombres, casi todos novohispanos, en favor de la causa realista, organizando un ejército con 40.000 plazas repartido en 15 divisiones por todo el virreinato, y estableciendo compañías milicianas en cada población, denominadas patriotas o fieles realistas, que, con una fuerza total de unos 45.000 hombres, se encargarían de velar por el orden en sus jurisdicciones bajo el mando de las élites locales. ${ }^{71}$

Gracias a la nueva táctica la insurgencia quedó reducida a unos cuantos grupos inconexos, pero también aumentó el gasto en defensa, lo que terminó por arruinar la ya mermada economía novohispana. Además, las constantes contribuciones y las obligaciones del servicio fomentaron el desapego de gran parte de la sociedad hacia la Corona y supuso que buena parte de la población se armara y organizara militarmente, lo que terminará volviéndose contra las autoridades en $1821 .^{72}$

\section{Conclusiones}

Tras el estallido insurgente, en apenas un mes Calleja transformó las milicias potosinas, formadas por vecinos para la defensa de su región, en una fuerza expedicionaria cuyos miembros, con el tiempo, se profesionalizaron. También, fruto de los ascensos y el reclutamiento llevados a cabo, se produjo un rejuvenecimiento y una «criollización» de la oficialidad, tendencia que se fue consolidando durante los años que duró la guerra. La formación de esta considerable fuerza de casi tres mil hombres en tan poco tiempo fue un gran mérito del comandante que, como líder indiscutible de la región, contó con el apoyo de los diversos sectores de la sociedad potosina.

70 Despacho de virrey de Nueva España para Félix Calleja, Cádiz, 16 de noviembre de 1812, AGMS, $1^{\text {a }}, 1^{\text {a }}, \mathrm{C}-532$. Con su ejército, Calleja impidió que la insurgencia consumase la independencia, ya que conocía perfectamente el territorio, sus habitantes, sus enemigos y hasta donde podía contar con sus tropas, por lo que sus movimientos siempre fueron calculados y seguros (fue a Cuautla obligado por el virrey), aunque en ocasiones pecó de lentitud. Alamán, 1939, 71-72. Hernández, 2011, 44-45.

71 Esta estrategia tuvo una influencia capital en la organización de las fuerzas armadas del México independiente. Kahle, 1997, 83-84. Ortiz, 2007, 292-294.

72 Ante el desgaste de una década de conflicto, pocos dudaron en apoyar al coronel Agustín de Iturbide con su proyecto independentista de paz y mantenimiento de privilegios recogido en el Plan de Iguala. De esta manera, paradójicamente, fueron las fuerzas realistas organizadas por Calleja (tanto las que formaban el ejército como las milicias de fieles) las que proclamaron la independencia. Benavides, 2014, 331. 
$\mathrm{Al}$ unirse con las tropas procedentes de México y Puebla comandadas por Flon, se formó el Ejército del Centro, un contingente de unos seis mil hombres, pertenecientes a once cuerpos diferentes. A pesar de sus carencias armamentísticas y de su escasa o nula experiencia en combate, esta fuerza improvisada fue capaz de derrotar a los insurgentes en Aculco, Guanajuato, Puente Calderón y Zitácuaro, y en multitud de pequeñas escaramuzas por buena parte del virreinato durante el año y medio que estuvo en campaña. ${ }^{73}$

El Ejército del Centro estaba formado por una tropa novohispana y la mayoría de los oficiales eran americanos, aunque bajo las órdenes de mandos peninsulares. Al igual que sucedía en la administración civil y religiosa, los europeos copaban los puestos más elevados del sector militar. Sin embargo, los mandos del Ejército del Centro no fueron enviados desde la península ex profeso. Eran oficiales con largas trayectorias profesionales y personales en Nueva España y conocían el territorio y la idiosincrasia de sus habitantes. Los oficiales como Calleja, Flon y otros, militares y milicianos, que fueron adquiriendo un gran protagonismo durante la guerra, desdeñaban a los mandos enviados desde la Península por su desconocimiento de la realidad novohispana y su altanería. Estos, por su parte, menospreciaban los méritos de los que habían hecho carrera en América, y no los consideraban dignos de confianza porque estaban «acriollados». Las continuas disputas de Calleja con altos rangos militares enviados desde España, como el virrey Venegas y el brigadier Cruz, demuestran las diferencias y tensiones entre ambos grupos.

Por tanto, podría decirse que el Ejército del Centro fue una fuerza novohispana que luchó contra otra fuerza novohispana con una composición social similar (la única diferencia entre ambos contingentes era el componente indígena, abundante entre los insurgentes y testimonial en la fuerza realista). Es decir, si bien para facilitar la narración de la Guerra de Independencia se habla de dos bandos, el de los «realistas», que luchaban en defensa de las autoridades virreinales, y el de los insurgentes, que se rebelaron siguiendo a Hidalgo y Allende y después a Morelos y otros líderes, en realidad se trata de un conflicto mucho más complejo, en el que ambas partes eran un mismo producto de la crisis de la Monarquía de 1808, pero

73 Como se puede apreciar en la correspondencia, las carencias humanas y materiales de este ejército, así como su escasa disciplina, contrariaban a Calleja, un militar de carrera que fue instructor en una academia militar. Sin embargo, las victorias logradas sobre los insurgentes y sus quince años de experiencia como comandante de milicias, sirvieron para que el general se ganara su apoyo y respeto, como quedó demostrado en su enfrentamiento con el virrey Venegas. Extracto de la correspondencia del brigadier Félix Calleja, noviembre y diciembre de 1810, AGN, OG, 170. Benavides, 2014, 316. 
que siguieron distintos caminos en 1810. Como se ha señalado, la mayoría del Ejército del Centro eran miembros de la sociedad civil, de origen diverso, tanto geográfico como social, que reaccionaron contra la insurgencia. Pero entonces cabría preguntarse por qué tomaron las armas frente a los rebeldes, en lugar de unirse a ellos.

Entre los muchos factores que pudieron influir, al margen de la lealtad al rey, que también se puede apreciar en algunos miembros de las fuerzas insurgentes, no se debe menospreciar la importancia de la motivación económica (salario elevado), pero sobre todo habría que considerar el papel de ciertas autoridades regionales con la capacidad de movilizar a la sociedad local. Ahí radica la importancia de que los mandos del Ejército del Centro, al margen de sus galones o de su origen criollo o peninsular, fueran auténticos líderes regionales. Calleja y Flon organizaron una fuerza de cierta envergadura en un breve espacio de tiempo gracias a su ascendencia sobre la población de las regiones donde llevaban años asentados (aproximadamente el $75 \%$ del Ejército del Centro procedía de San Luis y Puebla).$^{74}$ Este liderazgo, que conllevaba una mayor disciplina y obediencia de las tropas, también facilitó el éxito militar sobre las fuerzas insurgentes, cuyo grado de organización en esta primera etapa de la guerra era notablemente inferior.

En un segundo nivel, los personajes relevantes de menor rango, temerosos ante la revuelta social que había estallado, formaron contingentes con su personal dependiente y se unieron al ejército como oficiales, lo que además les garantizaba una mayor preeminencia. Esta fue la razón, al margen del estímulo que podía suponer un sueldo elevado, por la que se alistaron muchos reclutas que por su situación social, especialmente los peones de haciendas, no tenían la posibilidad de contradecir a sus patrones. En esta comunión de influencia social y mando militar pudo empezar a perfilarse la figura del caudillo, que tuvo un papel protagonista durante el siglo XIX, ya que con el transcurrir de la guerra los grupos de poder se fortalecieron dentro de la institución militar, que fue quedando bajo sus órdenes, garantizando así el mantenimiento del statu quo y consolidando su primacía.

Recibido el 7 de febrero de 2017 Segunda versión el 7 de agosto de 2017 Aceptado el 5 de septiembre de 2017

74 Cabría recordar que la mayoría de las cifras mencionadas son proyecciones de datos a partir de las informaciones parciales, más o menos numerosas, obtenidas a partir de la documentación conservada. 


\section{Referencias bibliográficas}

Alamán, Lucas, Historia de México, desde los primeros movimientos que prepararon su independencia en el año de 1808 hasta la época presente, México, Fondo de Cultura Económica, 1985.

Alamán, Lucas, Semblanzas e ideario, México, Ediciones de la Universidad Nacional Autónoma, 1939.

Albi de la Cuesta, Julio, Banderas olvidadas. El ejército realista en América, Madrid, Cultura Hispánica, 1990.

Annino, Antonio y Guerra, François-Xavier (coords.), Inventando la nación, Iberoamérica, México, FCE, 1991.

Archer, Christon I., El ejército en el México borbónico, 1760-1810, México, FCE, 1983.

Archer, Christon I., "La causa buena": The Counterinsurgency Army of New Spain and the Ten Years' War», en Rodríguez, Jaime E. (ed.), The Independence of Mexico and the Creation of the New Nation, Los Ángeles, UCLA, 1989, 85-108.

Archer, Christon I., «La revolución militar de México: Estrategia, tácticas y logísticas durante la guerra de independencia», en Vázquez, J. (coord.), Interpretaciones sobre la Independencia de México, México, Nueva Imagen, 1997, 123-176.

Archer, Christon, «En busca de una victoria definitiva: el ejército realista de Nueva España, 1810-1821», en Terán, Marta y Serrano, José A. (eds.), Las guerras de independencia en la América Española, Zamora, Colegio de Michoacán, 2002a, 423-438.

Archer, Christon, «Ciudades en la tormenta: el impacto de la contrainsurgencia realista en los centros urbanos, 1810-1821», en Broseta, Salvador et alii (eds.), Las ciudades y la guerra, 1750-1898, Castellón, Universidad Jaume I, 2002b, 335-360.

Archer, Christon I., «Peanes e himnos de victoria de la guerra de independencia mexicana. La gloria, crueldad y “demonización” de los gachupines, 181021», en Rodríguez, Jaime E. (coord.), Revolución, independencia y las nuevas naciones de América, Madrid, Mapfre, 2005, 229-257.

Ávila, Alfredo y Guedea, Virginia (coords.), La independencia de México: temas e interpretaciones recientes, México, UNAM, 2007.

Benavides, Juan José, De milicianos del rey a soldados mexicanos. Milicias y sociedad en San Luis Potosí (1767-1824), Madrid, CSIC, 2014.

Benavides, Juan José, «El germen de un ejército: Félix Calleja y la creación de la fuerza realista potosina en 1810», Revista Complutense de Historia de América, 42, Madrid, 2016, 221-242.

Bernal, Graciela, «El papel de los subdelegados en la contrainsurgencia. Guanajuato, 1810-1812», en Fernández, Rafael; Gutiérrez, María Pilar y Arrioja, 


\section{LA COMPOSICIÓN SOCIAL DEL EJÉRCITO DEL CENTRO}

Luis (coords.), De reinos y subdelegaciones, Zamora, Colegio de Michoacán, 2014, 347-363.

Bernal, Graciela, «Sociedad y guerra: Actitudes ante la insurgencia en San Luis Potosí, 1810-1821», en Álvarez, Izaskun y Sánchez, Julio (eds.), Visiones y revisiones de la independencia americana: México, Centroamérica y Haití, Salamanca, Calatrava, 2005, 157-174.

Bustamante, Carlos María, Campañas del general Félix María Calleja, comandante en jefe del Ejército Real de Operaciones del Centro, México, Imprenta del Águila, 1828.

Carabarín, Alberto, El intendente Flon y el ocaso de la institución municipal, Puebla, Benemérita Universidad Autónoma de Puebla, 2005.

Chust, Manuel y Marchena, Juan (eds.), Las armas de la nación. Independencia y ciudadanía en Hispanoamérica (1750-1850), Madrid, Iberoamericana, 2007.

Chust, Manuel (coord.), 1808: la eclosión juntera en el mundo hispano, México, FCE, 2007.

Costeloe, Michael P., La respuesta a la Independencia. La España imperial y las revoluciones hispanoamericanas, 1810-1840, México, FCE, 1989.

Ferguson, Carol, The Spanish Tamerlaine? Felix Maria Calleja, Vicerroy of New Spain, 1813-1816, Dallas, Texas Christian University, 1973.

García, Rafael, Reforma y resistencia: Manuel de Flon y la intendencia de Puebla, México, Porrúa, 2000.

Guzmán, Moisés, «Milicia y poder: las bases del aspirantismo criollo», en Broseta, Salvador et alii (eds.), Las ciudades y la guerra, 1750-1898, Castellón, Universitat Jaume I, 2002, 471-488.

Guedea, Virginia, «El proceso de independencia y las juntas de gobierno en Nueva España (1808-1821)», en Rodríguez, Jaime E. (coord.), Revolución, independencia y las nuevas naciones de América, Madrid, Mapfre, 2005, 215-228.

Hamnett, Brian, Raíces de la insurgencia en México: Historia regional (17501824), México, FCE, 1986.

Hernández, Héctor, «Las campañas de Félix Calleja contra la insurgencia y la lucha por el poder en el gobierno virreinal (1808-1816)», en Olveda, Jaime (coord.), Los comandantes realistas y la guerra de independencia, Zapopan, Colegio de Jalisco, 2011, 21-62.

Kahle, Günter, El ejército y la formación del estado en los comienzos de la independencia de México, México, FCE, 1997.

Marchena, Juan; Caballero, Gumersindo y Torres, Diego, El ejército en América antes de la independencia. Ejército regular y milicias, 1750-1815, Madrid, Mapfre, 2005.

Marchena, Juan y Kuethe, Allan (eds.), Soldados del rey: el ejército borbónico en la América colonial en vísperas de la independencia, Castellón, Universitat Jaume I, 1982.

Mc Alister, Lyle, El fuero militar en la Nueva España, México, UNAM, 1982. 
Monroy, María Isabel y Calvillo, Tomás, Breve historia de San Luis Potosí, México, Colegio de México, 1997.

Navarro García, Luis, Umbral de la independencia: El golpe fidelista de México en 1808, Cádiz, Universidad de Cádiz, 2009.

Núñez y Domínguez, José de, La virreina mexicana: doña María Francisca de la Gándara de Calleja, México, Imprenta Universitaria, 1950.

Olveda, Jaime, De la Insurrección a la Independencia. La guerra en la región de Guadalajara, Zapopan, Colegio de Jalisco, 2011.

Ortiz, Juan, «Félix Calleja, de héroe a villano», en Chust, Manuel y Mínguez, Víctor (eds.), La construcción del héroe en España y México (1789-1847), Valencia, Universitat de Valencia, 2003, 337-356.

Ortiz, Juan, «La nacionalización de las fuerzas armadas en México, 1750-1867», en Chust, M. y Marchena, J. (eds.), Las armas de la nación. Independencia y ciudadanía en Hispanoamérica (1750-1850), Madrid, Iberoamericana, 2007, 291-323.

Ortiz, Juan, Guerra y gobierno. Los pueblos y la independencia de México, México, Colegio de México, 2014.

Pérez-Toledo, Sonia, Los hijos del trabajo. Los artesanos de la ciudad de México, 1780-1853, México, Colegio de México, 1996.

Portillo Valdés, José M., Crisis atlántica: autonomía e independencia en la crisis de la monarquía hispana, Madrid, Fundación Carolina, 2006.

Rangel Silva, José Alfredo, Capitanes a guerra, linajes de frontera. Ascenso y consolidación de las élites en el oriente de San Luis (1617-1823), México, Colegio de México, 2008.

Rangel Silva, José Alfredo, «Milicias en el oriente de San Luis Potosí, 1793-1813», en Chust, M. y Marchena, J. (eds.), Las armas de la nación. Independencia y ciudadanía en Hispanoamérica (1750-1850), Madrid, Iberoamericana, 2007, 53-77.

Rodríguez O., Jaime E., El proceso de la independencia de México, México, Instituto Mora, 1992.

Ruiz de Gordejuela, Jesús, El vizcaíno Gabriel de Yermo y los voluntarios de Fernando VII. El golpe de estado que frustró la independencia de México, México, INHERM, 2012.

Ruiz Ibáñez, José Javier (coord.), Las milicias del rey de España. Sociedad, política e identidad en las Monarquías Ibéricas, México, FCE, 2009.

Suárez, Santiago Gerardo, Las Milicias, instituciones militares hispanoamericanas, Caracas, Academia Nacional de Historia, 1984.

Thibaud, Clement, Repúblicas en armas. Los ejércitos bolivarianos en la guerra de independencia en Colombia y Venezuela, Bogotá, Planeta, 2003.

Van Young, Eric, La otra rebelión. La lucha por la independencia de México, 1810-1821, México, FCE, 2007.

Vázquez, Josefina Zoraida (coord.), Interpretaciones sobre la Independencia de México, México, Nueva Imagen, 1997. 


\section{LA COMPOSICIÓN SOCIAL DEL EJÉRCITO DEL CENTRO}

Vázquez, María del Carmen, Puente de Calderón: las versiones de un célebre combate, México, UNAM, 2010.

Vega Juanino, Josefa, La institución militar en Michoacán en el último cuarto del siglo XVIII, Zamora, Colegio de Michoacán, 1986.

Velázquez, Primo Feliciano, Historia de San Luis Potosí, San Luis Potosí, Academia de Historia Potosina, 1982.

Von Wobeser, Gisela, Dominación colonial: la Consolidación de Vales Reales en Nueva España, 1804-1812, México, UNAM, 2003. 